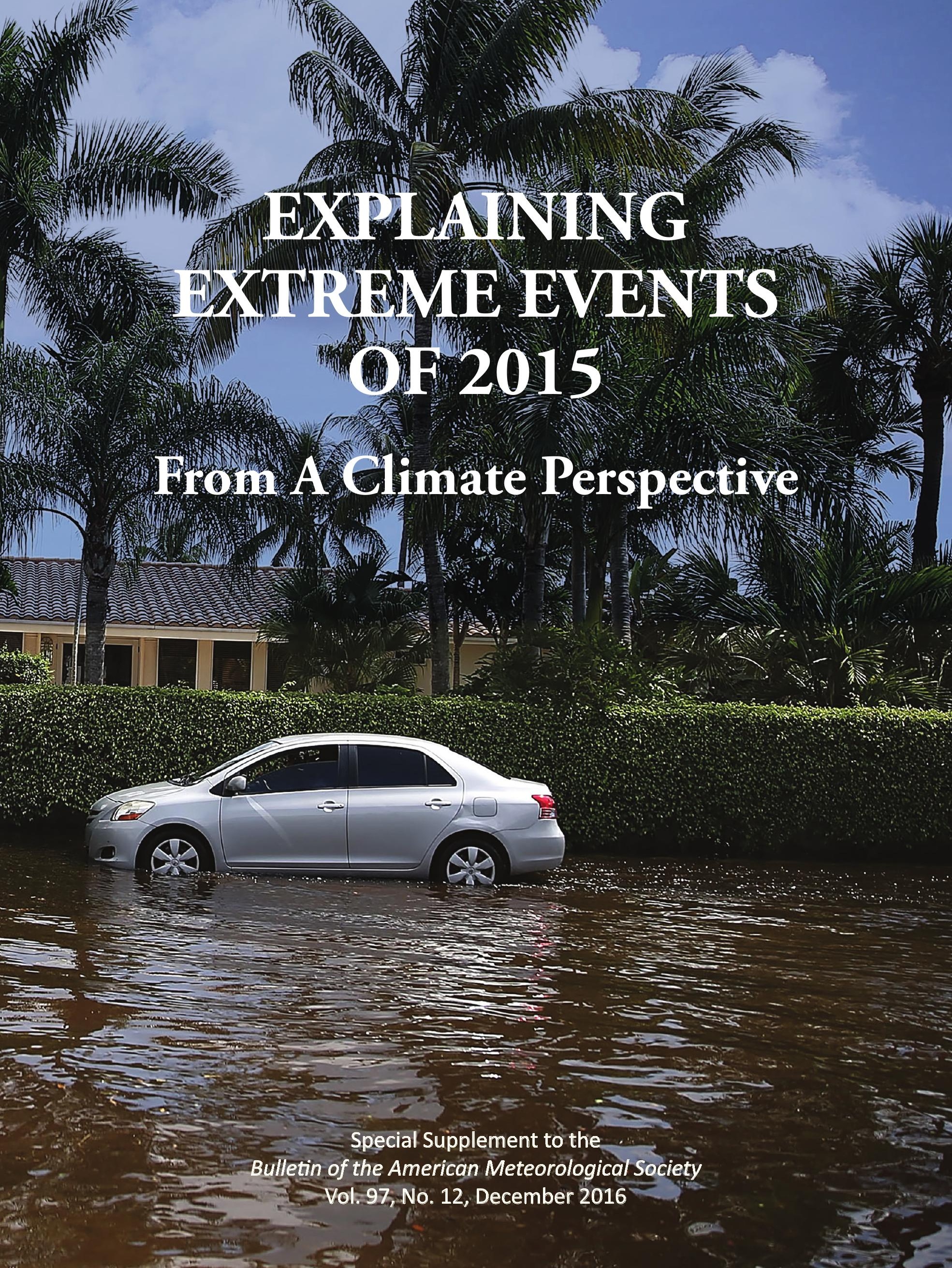




\section{EXPLAINING EXTREME \\ EVENTS OF 20I5 FROM A CLIMATE PERSPECTIVE}

\section{Editors}

Stephanie C. Herring, Andrew Hoell, Martin P. Hoerling, James P. Kossin, Carl J. Schreck III, and Peter A. Stott

Special Supplement to the

Bulletin of the American Meteorological Society

Vol. 97, No. I2, December 2016 


\section{CORRESPONDING EDITOR:}

Stephanie C. Herring, PhD

NOAA National Centers for Environmental Information

325 Broadway, E/CC23, Rm IB-I3I

Boulder, CO, 80305-3328

E-mail: stephanie.herring@noaa.gov

\section{Cover CRedit:}

CPhoto by Joe Raedle/Getty Images-A vehicle drives through flooded streets caused by a combination of the lunar orbit which caused seasonal high tides and what many believe is the rising sea levels due to climate change on September 30, 20I5, in Fort Lauderdale, Florida. South Florida is projected to continue to feel the effects of climate change, and many of the cities have begun programs such as installing pumps or building up sea walls to try and combat the rising oceans.

\section{HOW TO CITE THIS DOCUMENT}

Citing the complete report:

Herring, S. C., A. Hoell, M. P. Hoerling, J. P. Kossin, C. J. Schreck III, and P.A. Stott, Eds., 20I6: Explaining Extreme Events of 20 I5 from a Climate Perspective. Bull.Amer. Meteor. Soc., 97 (I 2), SI-SI 45.

Citing a section (example):

Partain, J. L., and Coauthors, 2016: An assessment of the role of anthropogenic climate change in the Alaska fire season of 2015 [in "Explaining Extremes of 2015 from a Climate Perspective”]. Bull. Amer. Meteor. Soc., 97 (I2), SI4-SI8, doi:I0.II75/BAMS-D-16-0149.

\section{EDITORIAL AND PRODUCTION TEAM}

Riddle, Deborah B., Lead Graphics Production, NOAA/NESDIS National Centers for Environmental Information,

Asheville, NC

Veasey, Sara W., Visual Communications Team Lead, NOAA/ NESDIS National Centers for Environmental Information, Asheville, NC

Love-Brotak, S. Elizabeth, Graphics Support, NOAA/NESDIS National Centers for Environmental Information,

Asheville, NC

Fulford, Jennifer, Editorial Support, Telesolv Consulting LLC, NOAA/NESDIS National Centers for Environmental Information, Asheville, NC

Griffin, Jessicca, Graphics Support, Cooperative Institute for Climate and Satellites-NC, North Carolina State University, Asheville, NC
Maycock, Tom, Editorial Support, Cooperative Institute for Climate and Satellites-NC, North Carolina State University, Asheville, NC

Misch, Deborah J., Graphics Support, Telesolv Consulting LLC, NOAA/NESDIS National Centers for Environmental Information, Asheville, NC

Osborne, Susan, Editorial Support, Telesolv Consulting LLC, NOAA/NESDIS National Centers for Environmental Information, Asheville, NC

Sprain, Mara, Editorial Support, LAC Group, NOAA/NESDIS National Centers for Environmental Information, Asheville, NC

Young, Teresa, Graphics Support, STG, Inc., NOAA/NESDIS National Centers for Environmental Information, Asheville, NC 


\section{TABLE OF CONTENTS}

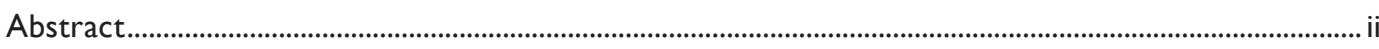

I. Introduction to Explaining Extreme Events of 2015 from a Climate Perspective.................................

2. Multimodel Assessment of Anthropogenic Influence on Record Global and Regional Warmth

During 2015 ........................................................................................................................................

3. What History Tells Us About 2015 U.S. Daily Rainfall Extremes ......................................................

4. An Assessment of the Role of Anthropogenic Climate Change in the Alaska Fire Season

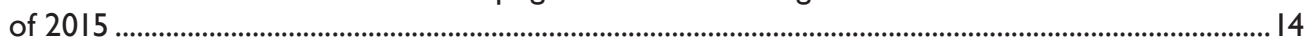

5. The 2014/15 Snowpack Drought in Washington State and its Climate Forcing ................................19

6. In Tide's Way: Southeast Florida's September 2015 Sunny-day Flood ................................................... 25

7. Extreme Eastern U.S. Winter of 2015 Not Symptomatic of Climate Change .....................................

8. The Role of Arctic Sea Ice and Sea Surface Temperatures on the Cold 2015 February

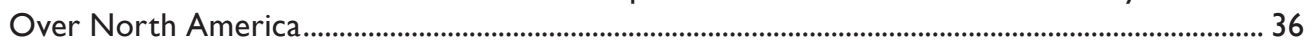

9. The 2015 Extreme Drought in Western Canada ................................................................................ 42

10. Human Contribution to the Record Sunshine of Winter 2014/15 in the United Kingdom .............47

II. The Role of Anthropogenic Warming in 2015 Central European Heat Waves ...................................5I

12. The 2015 European Heat Wave ....................................................................................................................

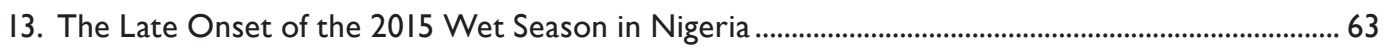

14. Human Influences on Heat-Related Health Indicators During the 2015 Egyptian Heat Wave .................................................................................................................................. 70

15. Assessing the Contributions of Local and East Pacific Warming to the 2015

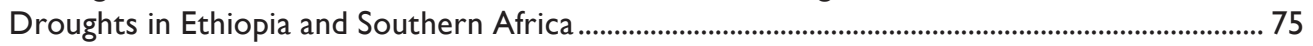

16. The Deadly Combination of Heat and Humidity in India and Pakistan in Summer 2015..................8I

17. The Heavy Precipitation Event of December 2015 in Chennai, India................................................... 87

18. Attribution of Extreme Rainfall in Southeast China During May 2015 ............................................. 92

19. Record-Breaking Heat in Northwest China in July 2015: Analysis of the Severity and Underlying Causes ........................................................................................................................... 97

20. Human Influence on the 2015 Extreme High Temperature Events in Western China................... 102

21. A Persistent Japanese Heat Wave in Early August 2015: Roles of Natural Variability and

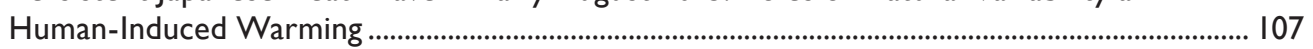

22. Climate Change and El Niño Increase Likelihood of Indonesian Heat and Drought........................ 113

23. Southern Australia's Warmest October on Record: The Role of ENSO and Climate Change....................................................................................................................................... 118

24. What Caused the Record-Breaking Heat Across Australia in October 2015? .............................. 122

25. The Roles of Climate Change and El Niño in the Record Low Rainfall in October 2015 in Tasmania, Australia.

26. Influences of Natural Variability and Anthropogenic Forcing on the Extreme 2015 Accumulated Cyclone Energy in the Western North Pacific

27. Record Low Northern Hemisphere Sea Ice Extent in March 2015 ............................................... 136

28. Summary and Broader Context.....................................................................................................141 
This fifth edition of explaining extreme events of the previous year (2015) from a climate perspective continues to provide evidence that climate change is altering some extreme event risk. Without exception, all the heat-related events studied in this year's report were found to have been made more intense or likely due to human-induced climate change, and this was discernible even for those events strongly influenced by the $2015 \mathrm{El}$ Niño. Furthermore, many papers in this year's report demonstrate that attribution science is capable of separating the effects of natural drivers including the strong 2015 El Niño from the influences of long-term human-induced climate change.

Other event types investigated include cold winters, tropical cyclone activity, extreme sunshine in the United Kingdom, tidal flooding, precipitation, drought, reduced snowpack in the U.S. mountain west, arctic sea ice extent, and wildfires in Alaska. Two studies investigated extreme cold waves and monthly-mean cold conditions over eastern North America during 2015, and find these not to have been symptomatic of human-induced climate change. Instead, they find the cold conditions were caused primarily by internally generated natural variability. One of these studies shows winters are becoming warmer, less variable, with no increase in daily temperature extremes over the eastern United States. Tropical cyclone activity was extreme in 2015 in the western North Pacific (WNP) as measured by accumulated cyclone energy (ACE). In this report, a study finds that human-caused climate change largely increased the odds of this extreme cyclone activity season. The 2015 Alaska fire season burned the second largest number of acres since records began in 1940. Investigators find that human-induced climate change has increased the likelihood of a fire season of this severity.

Confidence in results and ability to quickly do an attribution analysis depend on the "three pillars" of event attribution: the quality of the observational record, the ability of models to simulate the event, and our understanding of the physical processes that drive the event and how they are being impacted by climate change. A result that does not find a role for climate change may be because one or more of these three elements is insufficient to draw a clear conclusion. As these pillars are strengthened for different event types, confidence in the presence and absence of a climate change influence will increase.

This year researchers also link how changes in extreme event risk impact human health and discomfort during heat waves, specifically by looking at the role of climate change on the wet bulb globe temperature during a deadly heat wave in Egypt. This report reflects a growing interest within the attribution community to connect attribution science to societal impacts to inform risk management through "impact attribution." Many will watch with great interest as this area of research evolves in the coming years. 


\title{
II. THE ROLE OF ANTHROPOGENIC WARMING IN 2015 CENTRAL EUROPEAN HEAT WAVES
}

\author{
Sebastian Sippel, Friederike E. L. Otto, Milan Flach, and Geert Jan van Oldenborgh
}

\author{
Station-based observations and bias-corrected model simulations show that the frequency of \\ short-term heat waves in central Europe has increased, albeit quantitative estimates of risk ratios \\ differ considerably between methods.
}

Summer 2015 in Europe. The summer 2015 in Europe was highly unusual, as persistent heat and dryness prevailed in large parts of the continent. In central and eastern Europe, a combination of record-low seasonal rainfall (Orth et al. 2016) and record-high monthly July/August temperatures were observed over an area stretching from France to western Russia (Supplemental Fig. S11.1). The anomalous temperatures were caused by a sequence of four intense heat waves that struck the region from the end of June to early September (e.g., Fig. 11.1a). It is precisely the few-day heat that causes problems with human health, especially when combined with high humidity (McGregor et al. 2010). We analyze seasonal maxima of 3-day mean temperature ( Tair $_{3 \text {, max }}$ ) and seasonal maxima of 3-day daily maximum wet bulb temperature $\left(\right.$ WBTX $\left._{3 \mathrm{~d} \text {, max }}\right)$, a measure of human thermal discomfort that combines temperature and humidity and is a proxy for heat stress on the human body (Fischer and Knutti 2013; Sherwood and Huber 2010).

The series of heat waves began with a strongly meandering jet stream, that is summertime "omegablocking" (Dole et al. 2011), and the advection of very warm subtropical air into central and western Europe (Supplemental Fig. S11.1). Later in the season, the jet stream was displaced to the north, so that stable high-pressure systems could prevail over central and eastern Europe bringing heat there. The first heat wave in early July was hence most pronounced in western parts of the continent, while south-central and east-central Europe experienced the highest

AFFILIATIONS: SIPPEL-Max Planck Institute for Biogeochemistry, Jena, Germany; OTTO-Environmental Change Institute, University of Oxford, Oxford, United Kingdom; FLACH-Max Planck Institute for Biogeochemistry, Jena, Germany; van OldenBorgh-Weather and Climate Modeling, Koninklijk Nederlands Meteorologisch Instituut, De Bilt, Netherlands

DOI:I0.1175/BAMS-D-16-0150.I

A supplement to this article is available online (I0.1 I75 /BAMS-D-16-0150.2) temperatures in the subsequent heat waves later in the season (Fig. 11.1b).

Anomalies in the hottest 3-day mean temperature reached up to $+6^{\circ} \mathrm{C}$ relative to climatology (Figs. $11.1 \mathrm{c}, \mathrm{d})$, and temperature records were broken, including nationwide records (Kitzingen, Germany: $40.3^{\circ} \mathrm{C}$; https://weather.com/news/climate/news/europe-heat-wave-poland-germany-czech-august-2015), various station records stretching from France to the Balkan countries and southern Sweden (www .meteofrance.fr/actualites/26913226-episode -de-tres-fortes-chaleurs-en-france), nighttime temperatures (Vienna, Austria: $26.9^{\circ} \mathrm{C}$ ), record 3-day mean temperatures across central Europe (Fig. 11.1e), and inland water temperatures (e.g., Lake Constance). Europe experienced the hottest August ever recorded (NOAA 2016), and the entire summer season ranked third after the unusual summers of persistent heat in 2003 and 2010 with hotspots in France and western Russia, respectively (Barriopedro et al. 2011; Stott et al. 2004). This extraordinary sequence of events raises the question to what extent human-induced climate change played a role in short-term heat waves beyond natural climate variability.

A potential anthropogenic contribution to the summer 2015 heat events had already been investigated in near-real time (www.climatecentral.org /europe-2015-heatwave-climate-change), and in the present paper we build upon and substantiate the previous analysis. We investigate two diagnostics (Tair $_{3 \mathrm{~d}, \max }$ and WBTX $\mathrm{Wd,max}$ ) at four locations in longterm station-based observational records and in a large ensemble of consistently bias-corrected regional climate model simulations.

Methods and Data. First, we analyze long-term observational data (115 years of data for each station) from the ECA\&D dataset (Klein Tank et al. 2002) of four central and eastern European stations that 
(a)

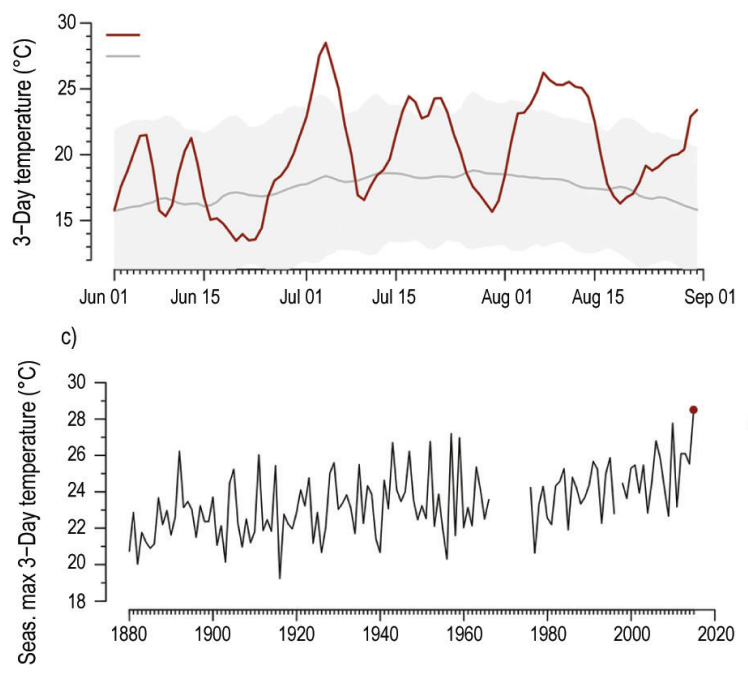

(d)
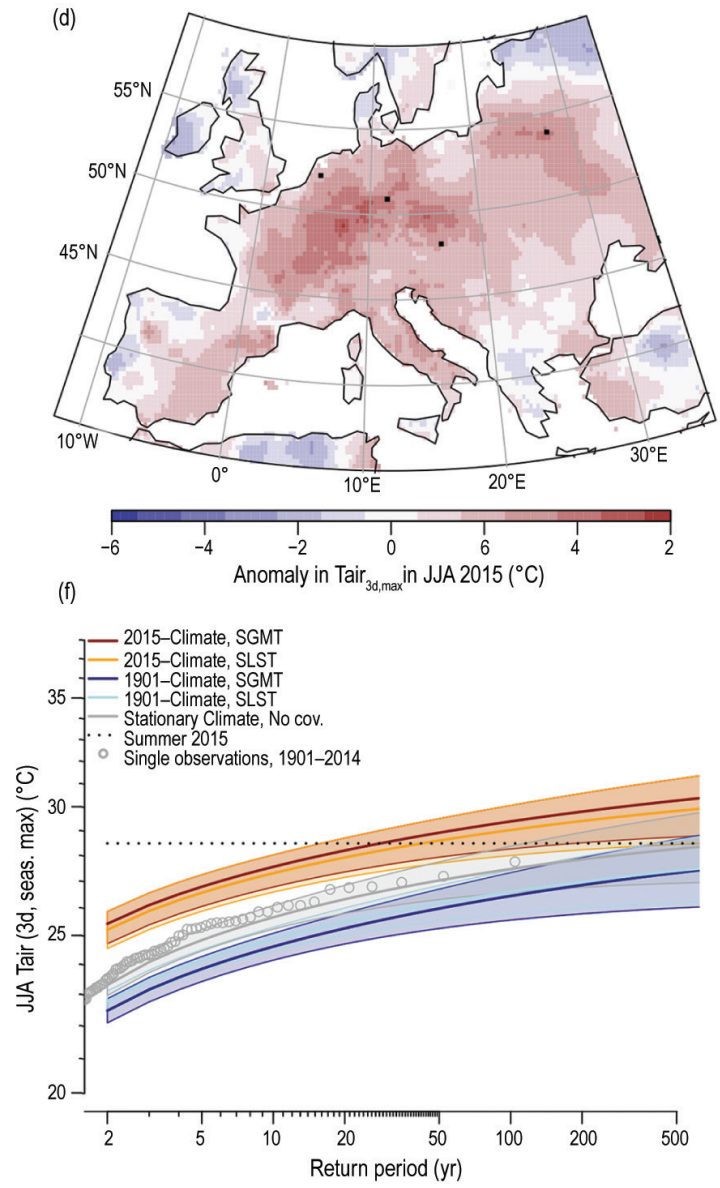

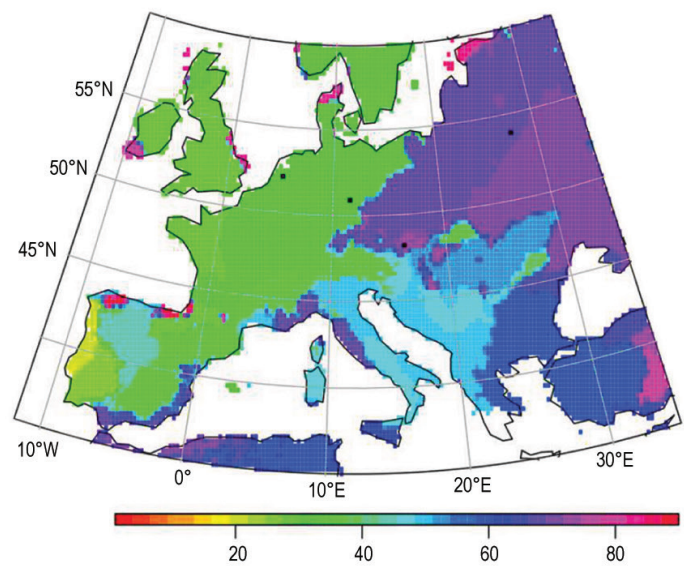

Day of seasonal heat record, JJA 2015 (days after 6 Jan 2015)

(e)
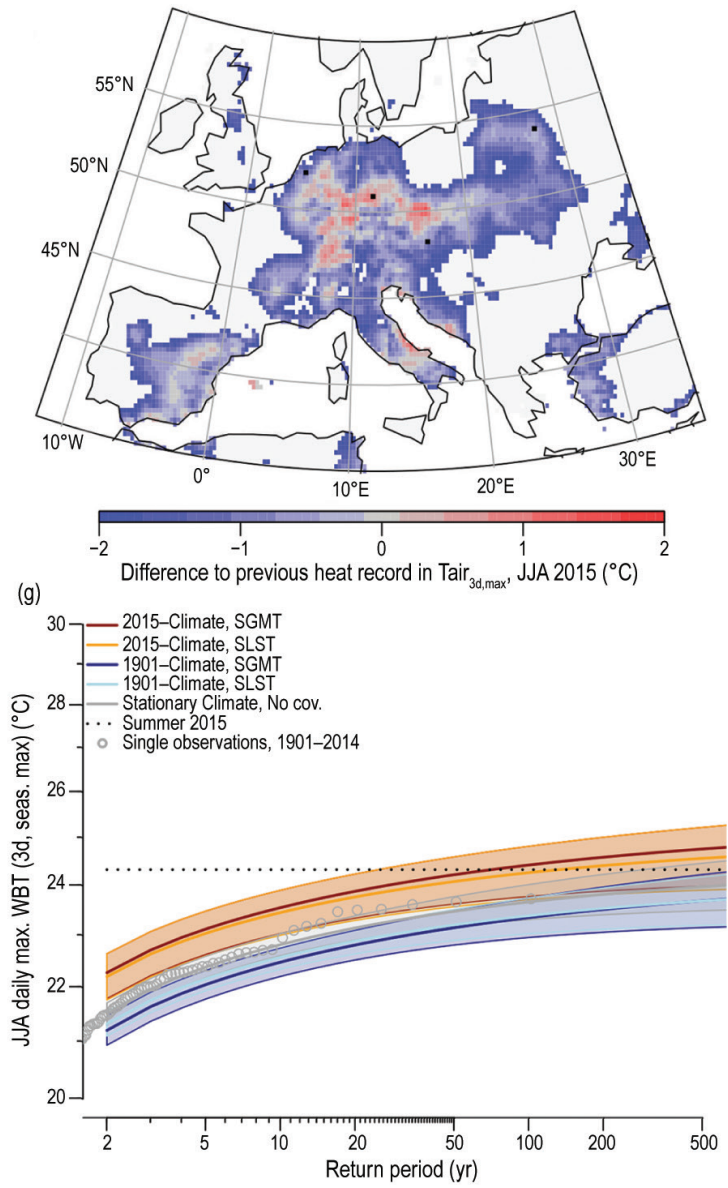

Fig. II.I. (a) Time series of 3-daily mean temperatures in summer 2015 at the Jena site (gray shading denotes $\pm 2-\sigma$ deviations relative to long-term interannual variability). (b) Day of seasonal temperature record in summer 2015. (c) Time series of seasonal maximum of 3-day mean temperatures ( Tair $_{3 d, \max }$ ) at the Jena site (summer 2015 is marked by a red dot). (d) Anomalies in Tair $_{3 \mathrm{~d}, \max }$ over Europe in summer 2015 relative to 198I-2010. (e) Difference to previous heat records (1950-2014) in Tair3d, max in the EOBS dataset. Positive differences indicate a new heat record in JJA 2015. (f),(g) Return time plots of GEV fits for Tair $_{3 \mathrm{~d}, \max }$ and WBTX ${ }_{3 \mathrm{~d}, \max }$, respectively, at the Jena site. Red (orange) lines indicate the fit for 2015 climate, dark-blue (light-blue) lines indicate the fit for $190 \mathrm{I}$ climate for a smoothed global mean temperature covariate (smoothed local summer temperature covariate). 
were affected by the heat waves in summer 2015 (Table 11.1), using data from 1901 onward. For each station, annual time series of Tair $_{3 \mathrm{~d} \text {, max }}$ and WBTX $\mathrm{Wd}_{3 \mathrm{~d}}$ $\max _{\text {max }}$ are calculated for July-August. $\mathrm{WBTX}_{3 \mathrm{~d} \text {, max }}$ is derived from daily maximum air temperature and vapor pressure (computed from relative humidity and daily mean temperature; www.srh.noaa.gov /epz/?n=wxcalc_rh) using an iterative procedure based on the psychrometric equation (Sullivan and Sanders 1974). Subsequently, generalized extreme value (GEV) statistical models are fitted to the data (Coles 2001) excluding the year 2015, using two different assumptions about changes in climate:

1) A "local" station-based covariate to the location parameter of the GEV (21-year smoothed local summer temperatures, SLST) as a proxy for any changes to local climate;

2) A "global" covariate to the location parameter (21-year smoothed global mean temperatures, SGMT) as a proxy for anthropogenic influence on climate (van Oldenborgh et al. 2012).

To avoid overfitting the relatively low number of data points, no dependence in the scale or shape parameter is assumed. Probability ratios (PR) based on the GEV as a metric to quantify human-induced change in the odds of extreme events $\left(\mathrm{PR}=\mathrm{p}_{\mathrm{ANT}} / \mathrm{p}_{\mathrm{NAT}}\right.$; Fischer and Knutti 2015) were obtained by calculating the probability of an event as warm or warmer than the observed 2015-event in a 2015-climate $\left(\mathrm{p}_{\mathrm{ANT}}\right)$, and in 1901 as a proxy for preindustrial climate.

Second, a model ensemble-based assessment using the global general circulation model HadAM3P $\left(1.875^{\circ} \times 1.25^{\circ} \times 15-\mathrm{min}\right.$ resolution $)$ and a dynamically downscaled regional variant (HadRM3P, $0.44^{\circ} \times$ $0.44^{\circ} \times 5$-min resolution) is conducted to complement the empirical analysis (see Massey et al. 2015 for all details regarding the model setup). Initial condition ensembles are generated for an anthropogenic scenario (ANT, $n=2286$ ), in which the model is driven by observed (2015) sea surface temperatures (SSTs) and anthropogenic forcings in atmosphere-only mode for 1 year at a time (starting 1 December; Massey et al. 2015); and a natural scenario (NAT, $\mathrm{n}=4414$ ) with all anthropogenic forcings (i.e., greenhouse gases, aerosols, halocarbons, and ozone) set to preindustrial levels and 11 different estimates of natural SSTs (Schaller et al. 2014). For each of the four locations (centered over a $1^{\circ} \times 1^{\circ}$ grid cell), a resampling bias correction strategy based on an observational constraint is applied to the model ensemble (Sippel et al. 2016) because the raw model output is notoriously too hot and dry (Black et al. 2015; Massey et al. 2015), severely compromising attribution statements (Supplemental Fig. S11.2). The seasonal maximum 21-day average temperature from the E-OBS dataset (Haylock et al. 2008) is used as a resampling

Table II.I. Location of meteorological stations and probability ratios estimated from observed and simulated data. Very large PR with a lower bound (5\% confidence interval) exceeding 10 are reported

as $>10$. PR from the model output are given as 5 th to 95 th percentile of 100 bootstrapped replicates $(n=1000)$. A PR range exceeding one would be significant at $95 \%$ confidence under a one-sided test. PR for the original model simulations (i.e., non-bias corrected) are indicated for comparison only. *The observed De Bilt series contains a well-known inhomogeneity in 1950, so the homogenized series from KNMI was used instead. **Humidity data was not available for Vienna and Minsk in the ECA\&D dataset for the year 2015.

\begin{tabular}{|c|c|c|c|c|}
\hline Station & De Bilt* & Jena & Minsk & Vienna \\
\hline Country & Netherlands & Germany & Belarus & Austria \\
\hline Location & $52^{\circ} 06^{\prime} \mathrm{N}, 5^{\circ} \mathrm{II} \mathrm{I}^{\prime} \mathrm{E}$ & $50^{\circ} 55.5^{\prime} \mathrm{N}, 11^{\circ} 35^{\prime} \mathrm{E}$ & $53^{\circ} 52^{\prime} \mathrm{N}, 27^{\circ} 32^{\prime} \mathrm{E}$ & $48^{\circ} 14^{\prime} \mathrm{N}, 16^{\circ} 2 \mathrm{I}^{\prime} \mathrm{E}$ \\
\hline $\mathbf{T a i r}_{3 \mathrm{~d}, \max , 2015}\left({ }^{\circ} \mathbf{C}\right)$ & 25.2 & 28.5 & 27.3 & 29.1 \\
\hline $\mathrm{PR}_{\text {HadRM3P, BC-anom }}$ & $1.2-1.4$ & I.1-2.5 & $1.7-2.5$ & $1.8-2.9$ \\
\hline $\mathrm{PR}_{\text {HadRM3P, BC-anom, obs. trend }}$ & $4.7-7.5$ & $4.1-8.7$ & $3.4-5.2$ & $>10$ \\
\hline $\mathrm{PR}_{\mathrm{EOBS}, \mathrm{GEV}-\mathrm{GMT}}$ & $>10$ & $>10$ & $>10$ & $>10$ \\
\hline $\mathbf{W B T}_{3 \mathrm{~d}, \max }\left(2015,{ }^{\circ} \mathrm{C}\right)$ & 22.9 & 24.3 & $\mathrm{n} / \mathrm{a}^{* *}$ & $\mathrm{n} / \mathrm{a}^{* *}$ \\
\hline $\mathrm{PR}_{\text {HadRM3P, BC-anom }}$ & $1.3-1.8$ & $1.5-3.1$ & $\mathrm{n} / \mathrm{a}^{* *}$ & $\mathrm{n} / \mathrm{a}^{* *}$ \\
\hline $\mathrm{PR}_{\mathrm{HadRM} 3 \mathrm{P}, \mathrm{BC} \text {-anom, obs. trend }}$ & $>10$ & $2.7-7.7$ & $\mathrm{n} / \mathrm{a}^{* *}$ & $\mathrm{n} / \mathrm{a}^{* *}$ \\
\hline $\mathrm{PR}_{\text {EOBS, GEV-GMT }}$ & $>10$ & $>8.6$ & $\mathrm{n} / \mathrm{a}^{* *}$ & $\mathrm{n} / \mathrm{a}^{* *}$ \\
\hline
\end{tabular}


constraint, and a percentile-based transfer function is calibrated for each station separately on the 1986-2010 climatology using an identical model setup (Massey et al. 2015). Subsequently, both natural and anthropogenic simulations are resampled using the derived relationship (Sippel et al. 2016). In contrast to widely used methods like quantile-quantile mapping, resampling retains the full multivariate structure and physical consistency of the model output but reduces the available ensemble size and chooses colder and wetter ensemble members, therefore alleviating the hot and dry bias (Sippel et al. 2016). In the context of event attribution, it is applied for the first time in this paper (Figs. 11.2a-d; see next section). To avoid potential mean biases due to station location, the mean of the resampled ensemble is adjusted to the station mean (Supplemental Figs. S11.2c,d). Results are demonstrated exemplarily for one station (Jena), and probability ratios are reported for all stations. tions. The 21-day resampling constraint considerably improves the representation of short-term heat waves by avoiding physically implausible simulations (Figs. $11.2 \mathrm{a}-\mathrm{d}$ ) and improving the simulated variability of heat waves (Supplemental Figs. S11.2c,d). The correlation structure between the temperature constraint and short-term heat stress $\left(\mathrm{WBTX}_{3 \mathrm{~d} \text {, max }}\right)$ in the observations is reproduced in the resampled model ensemble but not in the original model ensemble (Figs. 11.2a,c). This indicates that robust attribution statements for impact-related, and thus multivariate quantities (such as $\mathrm{WBTX}_{3 \mathrm{~d} \text {, max }}$ ), require a physically consistent bias correction of model output.

Consistent with the observations, the model-based assessment shows a shift in the return periods toward more frequent and more pronounced summer heat stress (Fig. 11.2b) in all locations (Table 11.1) and both bias-corrected and original simulations. The probability ratios derived from the bias-corrected
Results and Discussion. The statistical analysis of estimated return times of Tair $_{3 \mathrm{~d} \text {, max }}$ reveals that 2015-like heat events occur in present day climate approximately every 27 years in Jena with the onesided $5 \%$ lower confidence bound at 16 years (Fig. 11.1). Including both the local and global climate change covariates into the GEV fit demonstrates a profound increase in return times of those types of events relative to earlier years for both Tair $_{3 \mathrm{~d}}$, ${ }_{\max }$ and $\mathrm{WBTX}_{3 \mathrm{~d}, \max }$ in Jena (Figs. 11.1f,g) and all other locations with probability ratios typically exceeding a value of 10 (Table 11.1). The intensity of heat waves increases by about $3^{\circ} \mathrm{C}$ in Tair $_{3 \mathrm{~d}, \max }$ but only $1.1^{\circ} \mathrm{C}$ in WBTX $_{3 \mathrm{~d} \text {, max }}$ (Figs. 11.1f,g). In spite of this difference, the increase in the probability ratio is similar.

A similar analysis is conducted in a very large ensemble of model simula- (a)
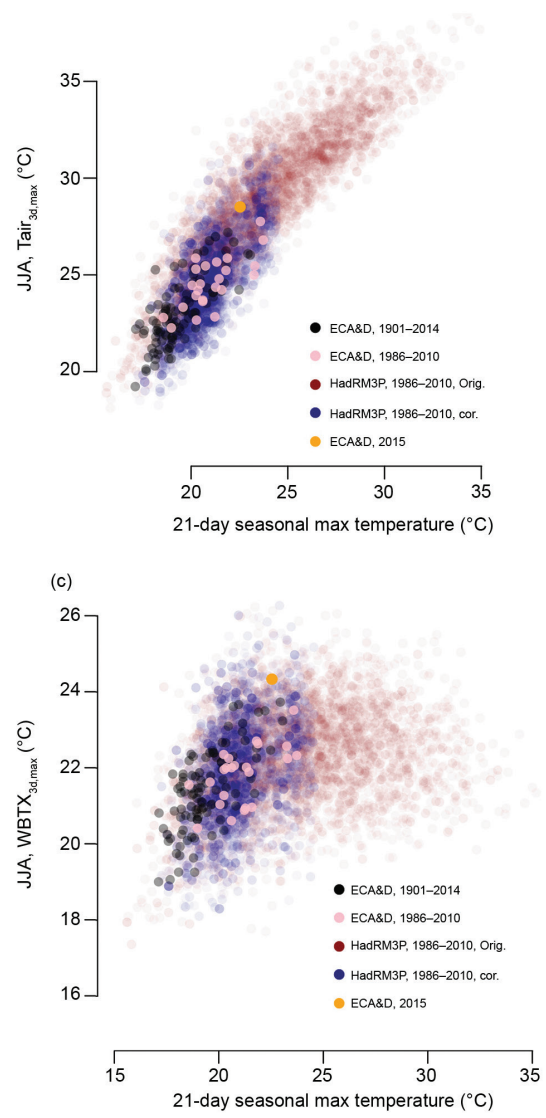
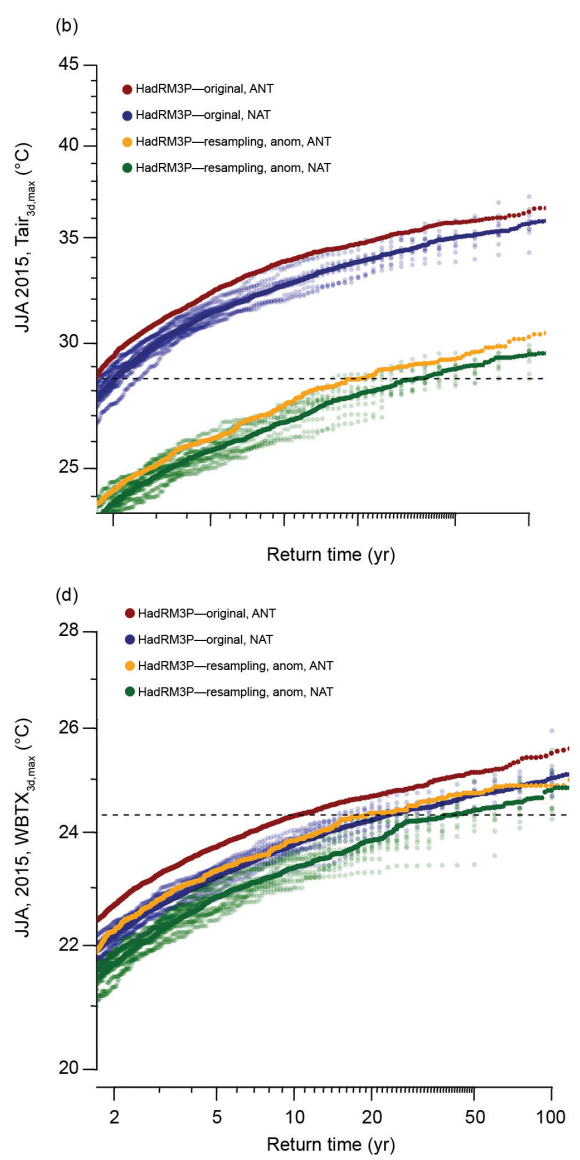

FIG. II.2. (a),(c) Correlation between 2 I-day seasonal maximum temperature (observational constraint for resampling bias correction) and impact-related quantities ( Tair $_{3 \mathrm{~d}, \max }$ and $\mathrm{WBTX}_{3 \mathrm{~d}, \max }$, respectively). Pink dots correspond to 1986-2010, the period used for calibration of the bias correction resampling function. (b),(d) Return time plots for original and bias-corrected model output for Tair $_{3 d, \text { max }}$ and WBTX $3 d$, max , respectively. 
model ensembles range from 1.1 to $2.9\left(\right.$ Tair $\left._{3 \mathrm{~d}, \max }\right)$ for the four locations $\left(\mathrm{PR}=1.3-3.1\right.$ for $\mathrm{WBTX}_{3 \mathrm{~d} \text {, max }}$ in Jena and De Bilt), depending on the magnitude of the 2015 event, the model-simulated warming, and interannual variability. These estimates are thus lower than those estimated from the observations but can be largely explained by method- and datarelated differences. For instance, the statistical method assumes that the trend is caused fully by anthropogenic factors, while the model analysis is based on a "real counterfactual" scenario but tends to underestimate warming trends in temperature extremes in Europe (Min et al. 2013). The mean observed change across all locations between 2015 and 1901 of $3.1^{\circ} \mathrm{C}\left(\right.$ Tair $\left._{3 \mathrm{~d}, \max }\right)$ and $2.2^{\circ} \mathrm{C}\left(\mathrm{WBTX}_{3 \mathrm{~d} \text {, }}\right.$ max $)$ is much larger than the original $\left(+1.1^{\circ} \mathrm{C}\right.$ in Tair $_{3 \mathrm{~d}}$, ${ }_{\max }$ and $+0.5^{\circ} \mathrm{C}$ in $\left.\mathrm{WBTX}_{3 \mathrm{~d}, \max }\right)$ and bias corrected $\left(+0.9^{\circ} \mathrm{C}\right.$ in Tair $_{3 \mathrm{~d}, \text { max }}$ and $+0.5^{\circ} \mathrm{C}$ in $\left.\mathrm{WBTX}_{3 \mathrm{~d}, \max }\right)$ model simulations. Hence, replacing the model-simulated warming by the observed change between 1901 and 2015 causes roughly a tripling of probability ratios for the bias-corrected simulations at all locations (e.g., 3.4-8.7 for Tair $_{3 \mathrm{~d}, \max }$ and 2.7 to exceeding 10 for $\mathrm{WBTX}_{3 \mathrm{~d} \text {, max }}$; cf., Table 11.1). Furthermore, uncertainties due to event selection (Christiansen 2015), dependence on the spatial and temporal scale (Angélil et al. 2014), high nonlinearity in attribution metrics such as the probability ratio (Supplemental Fig. S11.2), and a slightly higher variability on submonthly time scales in the model simulations than in the observations despite bias correction further contribute to model-data discrepancies and variability in the presented estimates of the probability ratios.

Conclusion. In conclusion, the multimethod analysis applied in this paper provides consistent evidence that human-induced climate change has contributed to the increase in the frequency and intensity of short-term heat waves and heat stress such as the central and eastern Europe 2015 event.

However, quantitative estimates of the risk ratio at local scales can differ widely depending on the exact methodologies applied, thus highlighting large method- and data-related uncertainties. In this study, due to the large discrepancy between observed and modeled trends in temperature extremes, the modelestimated probability ratios are lower than those estimated from the observations.

ACKNOWLEDGEMENTS. The work of Sippel and Flach was funded by the European Commission
Horizon 2020 BACI (Towards a Biosphere Atmosphere Change Index) Project (Grant 640176).

\section{REFERENCES}

Angélil, O., D. A. Stone, M. Tadross, F. Tummon, M. Wehner, and R. Knutti, 2014: Attribution of extreme weather to anthropogenic greenhouse gas emissions: Sensitivity to spatial and temporal scales. Geophys. Res. Lett., 41,2150-2155, doi:10.1002/2014GL059234.

Barriopedro, D., E. M. Fischer, J. Luterbacher, R. Trigo, and R. García-Herrera, 2011: The hot summer of 2010: Redrawing the temperature record map of Europe. Science, 332, 220-224, doi:10.1126 /science.1201224.

Black, M. T., D. J. Karoly, and A. D. King, 2015: The contribution of anthropogenic forcing to the Adelaide and Melbourne, Australia, heat waves of January 2014 [in "Explaining Extreme Events of 2014 from a Climate Perspective"]. Bull. Amer. Meteor. Soc., 96 (12), S145-S148.

Christiansen, B., 2015: The role of the selection problem and non-Gaussianity in attribution of single events to climate change. J. Climate, 28, 9873-9891, doi:10.1175/JCLI-D-15-0318.1.

Coles, S., 2001: An Introduction to Statistical Modeling of Extreme Values. Springer, 209 pp.

Dole, R., and Coauthors, 2011: Was there a basis for anticipating the 2010 Russian heat wave? Geophys. Res. Lett., 38, L06702, doi:10.1029/2010GL046582.

Fischer, E. M., and R. Knutti, 2013: Robust projections of combined humidity and temperature extremes. Nat. Climate Change, 3, 126-130, doi:10.1038 /nclimate1682.

—, and —, 2015: Anthropogenic contribution to global occurrence of heavy-precipitation and hightemperature extremes. Nat. Climate Change, 5, 560564, doi:10.1038/nclimate2617.

Haylock, M. R., N. Hofstra, A. M. G. Klein Tank, E. J. Klok, P. D. Jones, and M. New, 2008: A European daily high-resolution gridded data set of surface temperature and precipitation for 1950-2006. J. Geophys. Res., 113, D20119, doi:10.1029/2008JD10201.

Klein Tank, A. M. G., and Coauthors, 2002: Daily dataset of 20th-century surface air temperature and precipitation series for the European Climate Assessment. Int. J. Climatol., 22, 1441-1453, doi:10.1002 joc. 773 . 
Massey, N., and Coauthors, 2015: weather@ homedevelopment and validation of a very large ensemble modelling system for probabilistic event attribution. Quart. J. Roy. Meteor. Soc., 141, 1528-1545, doi:10.1002/qj.2455.

McGregor, G., P. Bessemoulin, K. Ebi, and B. Menne, Eds., 2010: Heat waves and health: Guidance on warning system development. WMO 1142, $114 \mathrm{pp}$. [Available online at www.who.int/globalchange /publications/heatwaves-health-guidance/en/.]

Min, E., W. Hazeleger, G. J. van Oldenborgh, and A. Sterl, 2013: Evaluation of trends in high temperature extremes in north-western Europe in regional climate models. Environ. Res. Lett., 8, 014011, doi:10.1088/1748-9326/8/1/014011.

NOAA, cited 2016: Climate at a glance: Global time series. [Available online at www.ncdc.noaa.gov/cag /time-series/global/europe/land/3/8/1912-2015.]

Orth, R., J. Zscheischler, and S. I. Seneviratne, 2016: Record dry summer in 2015 challenges precipitation projections in Central Europe. Sci. Rep., 6, 28334, doi:10.1038/srep28334.

Schaller, N., F. E. L. Otto, G. J. van Oldenborgh, N. R. Massey, S. Sparrow, and M. R. Allen, 2014: The heavy precipitation event of May-June 2013 in the upper Danube and Elbe basins [in "Explaining Extreme Events of 2013 from a Climate Perspective"]. Bull. Amer. Meteor. Soc., 95 (9), S69-S72.

Sherwood, S. C., and M. Huber, 2010: An adaptability limit to climate change due to heat stress. Proc. Natl. Acad. Sci. USA, 107, 9552-9555, doi:10.1073 /pnas.0913352107.

Sippel, S., and Coauthors, 2016: A novel bias correction methodology for climate impact simulations. Earth Syst. Dyn., 7, 71-88, doi:10.5194/esd-7-71-2016.

Stott, P. A., D. A. Stone, and M. R. Allen, 2004: Human contribution to the European heatwave of 2003. Nature, 432, 610-614, doi:10.1038/nature03089.

Sullivan, J., and L. D. Sanders, 1974: Method for obtaining wet-bulb temperatures by modifying the psychometric formula. NOAA Tech. Memo. EDS BOMAP-11, 8 pp. [Available online at http://docs .lib.noaa.gov/noaa_documents/NESDIS/TM_EDS /TM_EDS_BOMAP/TM_EDS_BOMAP_11.pdf.]

Van Oldenborgh, G. J., A. Van Urk, and M. Allen, 2012: The absence of a role of climate change in the 2011 Thailand floods [in "Explaing Extreme Events of 2011 from a Climate Perspective"]. Bull. Amer. Meteor. Soc., 93, 1047-1049. 


\section{Table 28.I. Summary of Results}

\section{ANTHROPOGENIC INFLUENCE ON EVENT}

\begin{tabular}{|c|c|c|c|}
\hline & INCREASE & DECREASE & NOT FOUND OR UNCERTAIN \\
\hline Heat & $\begin{array}{l}\text { Global Temperature (Ch. 2) } \\
\text { South India \& Sri Lanka (Ch. 2) } \\
\text { Central Europe (Ch. II) } \\
\text { Europe (Ch. I2) } \\
\text { Ethiopia and Southern Africa (Ch. I5) } \\
\text { N.W. China (Ch. I9) } \\
\text { W. China (Ch. 20) } \\
\text { Japan (Ch. 2I) } \\
\text { Indonesia (Ch. 22) } \\
\text { S. Australia (Ch. 23) } \\
\text { Australia (Ch. 24) }\end{array}$ & & Central Equitorial Pacific (Ch. 2) \\
\hline Cold & & Northeastern U.S. (Ch. 7) & $\begin{array}{l}\text { Mid-South Atlantic U.S. (Ch. 7) } \\
\text { N. America (Ch. 8) }\end{array}$ \\
\hline $\begin{array}{l}\text { Heat \& } \\
\text { Humidity }\end{array}$ & $\begin{array}{l}\text { Egypt (Ch. I4) } \\
\text { India \& Pakistan (Ch. 16) }\end{array}$ & & \\
\hline Dryness & $\begin{array}{l}\text { Indonesia (Ch. 22) } \\
\text { Tasmania (Ch. 25) }\end{array}$ & & \\
\hline $\begin{array}{l}\text { Heavy } \\
\text { Precipitation }\end{array}$ & China (Ch. I8) & & $\begin{array}{l}\text { Nigeria (Ch. 13) } \\
\text { India (Ch. I7) }\end{array}$ \\
\hline Sunshine & United Kingdom (Ch. I0) & & \\
\hline Drought & $\begin{array}{l}\text { Canada (Ch. 9) } \\
\text { Ethiopia and Southern Africa (Ch. I5) }\end{array}$ & & \\
\hline $\begin{array}{l}\text { Tropical } \\
\text { Cyclones }\end{array}$ & Western North Pacific (Ch. 26) & & \\
\hline Wildfires & Alaska (Ch. 4) & & \\
\hline $\begin{array}{l}\text { Sea Ice } \\
\text { Extent }\end{array}$ & & Arctic (Ch. 27) & \\
\hline $\begin{array}{l}\text { HIGH TIDE } \\
\text { FLOODS }\end{array}$ & SOUtheAstern U.S. (CH. 6) & & \\
\hline $\begin{array}{l}\text { SNOWPACK } \\
\text { DROUGHT }\end{array}$ & WASHINGTON U.S. (CH. 5) & & \\
\hline TOTAL & 23 & 2 & 5 \\
\hline
\end{tabular}




\section{METHOD USED}

Heat

Heat \& Humidity

Dryness

Heavy

Precipitation

Sunshine

Drought

Tropical

Cyclones

Wildfires

Sea Ice

Extent

High TIDE

FLOODS

SNOWPACK

DROUGHT

\section{Ch. 2: CMIP5 modeling}

Ch. II: Observations; weather@home modeling

Ch. 12: HadGEM3-A modeling

Ch. 15: CMIP5 modeling

Ch. 19: CMIP5 modeling with ROF; FAR

Ch. 20: CMIP5 modeling with ROF; FAR

Ch. 21: MIROC5-AGCM modeling

Ch. 22: Observations; CMIP5 modeling

Ch. 23: weather@home modeling; FAR

Ch. 24: BoM seasonal forecast attribution system and seasonal forecasts

Ch. 7: Observations; CMIP5 modeling

Ch. 8: AMIP (IFS model) modeling

Ch. 14: weather@home modeling

Ch. 16: Non-stationary EV theory; C20C+ Attribution Subproject

Ch. 22: Observations; CMIP5 modeling

Ch. 25: Observations; Modeling with CMIP5 and weather@home

Ch. 13: Observations; Modeling with CAM5.I and MIROC5

Ch. 17: Observations; Modeling with weather@home, EC-Earth and CMIP5

Ch. 18: HadGEM3-A-N216 modeling; FAR

Ch. I0: Hadley Centre event attribution system built on the high-resolution version of HadGEM3-A

Ch. 9: Observations; CMIP5 modeling; Trend and FAR analyses

Ch. 15: CMIP5 modeling, land surface model simulations, and statistical analyses

Ch. 26: GFDL FLOR modeling; FAR

12

Ch. 4: WRF-ARW optimized for Alaska with metric of fire risk (BUI) to calculate FAR

Ch. 27: OGCM modeling

CH. 6: Tide-gauge data; Time-dependent EV statistical model

Ch. 5: Observations; CeSMI modeling 